\title{
\#AdvocatingForChange: The Strategic Use of Hashtags in Social Media Advocacy
}

\author{
Gregory D. Saxton \\ Jerome N. Niyirora \\ Chao Guo \\ Richard D. Waters
}

\begin{abstract}
Social media continues to change how advocacy organizations mobilize, educate, and connect with their constituents. One of the most unique yet understudied tools available on social media platforms is the hashtag. Little research exists on how social work and advocacy organizations use hashtags, much less on how such use can be effective. This study examines the hashtag use by 105 constituent members of the National Health Council, a national US-based patient/health advocacy coalition. The study presents an inductive coding scheme of the types of hashtags employed, analyzes inter-sectoral differences in hashtag usage, and examines the relationship between hashtag use and measures of the effectiveness of social media messages.
\end{abstract}

Keywords: E-advocacy, hashtags, health, nonprofits, social media

Technology has significantly changed the landscape of social work practice, and perhaps no area has been impacted more over the past decade than community organizing and policy advocacy. Social media platforms dominate discussions of online advocacy because of their ease of use and abilities to tap into peer-to-peer networks to spread advocacy messages (Goldkind \& McNutt, 2014; Guo \& Saxton, 2014). Little research, however, has been conducted on the use of hashtags in relation to the success of advocacy efforts and social media engagement.

Hashtags, short words or phrases that follow the hash or pound sign (\#), such as \#StopDiabetes, \#HIV, or \#MarchforBabies, are used on social media platforms to brand advocacy movements, archive messages for the movement, and allow those not personally connected to a user to see and comment on messages that use the hashtag (Bruns \& Burgess, 2011). Using hashtags with online advocacy efforts allows movements to spread organically to like-minded individuals and organizations and to spread virally to other users of the social media platform. The purpose of this research is to determine how advocacy organizations use hashtags on Twitter, the types of hashtags being used, and whether using hashtags increases the level of engagement by those following advocacy efforts online.

This research examines eight months' of hashtag use on Twitter by 105 organizational members of the National Health Council, a large US-based patient advocacy association. Messages were examined for the presence of hashtags, the number and style of hashtags used, and how these hashtags impacted the number of times a message was retweeted, or shared, by other Twitter users. Regressions show hashtag use - and especially certain types

Gregory D. Saxton, PhD, is an Associate Professor in the Department of Communication at the University at Buffalo, SUNY. Jerome Niyirora, PhD, is an Assistant Professor in the College of Health Sciences and Management at the State University of New York Polytechnic Institute. Chao Guo, PhD, is an Associate Professor in the School of Social Policy \& Practice at the University of Pennsylvania. Richard D. Waters, PhD, is an Associate Professor in the School of Management at the University of San Francisco.

Copyright @ 2015 Advances in Social Work Vol. 16 No. 1 (Spring 2015), 154-169 
of hashtags - increased the level of engagement by those following the advocacy movements. This study informs theory and practice about how organizations can use social media platforms to best advocate for public policy and community organizing efforts.

\section{Prior Research}

\section{Social Work and e-Advocacy: From Web 1.0 to Social Media}

The spread of computer-media communications has led scholars to study its implications for social work practice (e.g., Anstadt, Burnette, \& Bradley, 2011; Perron, Taylor, Glass, \& Margerum-Leys, 2010). One of the most prolific areas of research has been e-advocacy. Advocacy-whether directly through lobbying or indirectly through grassroots mobilization, coalition building, or public education-is a core function of nonprofit organizations, for it is through such efforts that organizations can further represent the interests of their constituents (Guo \& Saxton, 2010; Mosley, 2013). Social work in particular has a strong professional commitment to social justice and advocacy (Queiro-Tajalli, Campbell, \& McNutt, 2003). Not surprisingly, a large body of research has shown how new media are changing the nature of advocacy work.

The first wave of research dealt with how early Internet technologies, especially as websites and email, were changing advocacy and activism practices (Hick \& McNutt, 2002). Scholars explored the advocacy opportunities and challenges presented by these electronic media (McNutt, 2008). Scholars also sought to develop an understanding of the determinants of e-advocacy activities (Goldkind, 2014) as well as what makes for effective use of the website for electronic advocacy efforts (Edwards \& Hoefer, 2010).

With the widespread and rapid adoption of social media platforms, a growing body of literature is now beginning to explore the intersection of social media and advocacy work. The earliest studies looked at adoption, or whether nonprofit advocacy organizations were using social media tools (Bortree \& Seltzer, 2009). The next wave explored managers' perceptions of social media for advocacy work (Obar, Zube, \& Lampe, 2012) along with the potential challenges of using social media tools (Goldkind \& McNutt, 2014). Research has also explored how these organizations were using social media for advocacy work (Guo \& Saxton, 2014).

\section{e-Advocacy Messages and Their Effectiveness}

An examination of social media-based advocacy efforts ultimately involves a focus on organization-audience communication. The primary communicative tool on all social media platforms is the series of regular, brief discrete messages - the tweet, the status update, the video, or the photo - that is sent to an organization's followers on Twitter, Facebook, YouTube, or Instagram, respectively. As a result, recent social media research in both a general organizational context (Lovejoy \& Saxton, 2012; Waters \& Jamal, 2011), as well as in the context of organizational advocacy, has come to focus on the nature of the messages organizations are sending. For instance, in a study of tweets (Twitter messages) sent by 150 large advocacy organizations, Guo and Saxton (2014) found the most prevalent advocacy tactics reflected in the tweets were public education and grassroots lobbying with 
some manifestations of research, coalition-building, public events/direct action, and voter registration and education. There were few instances of media advocacy, administrative lobbying, direct lobbying, or judicial advocacy.

While the above studies are invaluable, scholars have yet to examine the efficacy of advocacy work on social media. A variety of potential approaches could be pursued, such as looking at the impact on policy or attitudinal change. Although undoubtedly worthwhile, communication and public relations scholars have recently found an interesting alternative: examining the relationship between organizations' social media messages and the immediate audience reaction that manifests in the form of such actions as liking, commenting on, or sharing an organization's message on Facebook or retweeting (sharing) or favoriting (archiving) a message on Twitter (Saxton \& Waters, 2014). This ability to measure the almost real-time public reaction to an organization's advocacy messages facilitates a shift in measurement from the perceptual to the behavioral realm and provides organizations with a quantitative and comparable gauge to measure the relative effectiveness of their advocacy messaging strategies.

\section{Here Comes the Hashtag}

Social media have engendered new forms of communicating and interacting with the public. One of the most innovative tools is the hashtag. Since Twitter employee Chris Messina sent the first ever tweet containing a hashtag in 2007 (Kirkpatrick, 2011), hashtags have become popular and spread to other social media platforms.

Hashtags indicate topics or themes, and they represent an important innovation in social media communication. First, the use of hashtags is powerful because it is participatory. Hashtags are not decided in advance by a pre-determined set of users. The hashtag system constitutes a decentralized, user-generated tagging, organizing, and classification system. The hashtag classifies messages, improves searchability, and allows the organization to link messages to existing knowledge and action communities. It is this community element that undergirds the power of hashtags. Briefly put, hashtags can lead to the formation of ad hoc publics (Bruns \& Burgess, 2011) of networks that develop around the hashtag. These networks/communities can be ephemeral and arise in response to emergencies and crises, or they can be more stable, long-term communities of practice or knowledge that develop to spread ideas, news, or opinions on a given topic.

Despite their potential importance, neither scholars nor nonprofit organizations have closely examined hashtags. Two areas that have not been addressed to date are the use of hashtags in advocacy work and the determinants of the effectiveness of organizations' advocacy messages. This study addresses these areas by examining the nature and efficacy of advocacy organizations' communication on Twitter, focusing on the role of hashtags in connecting with audiences. 


\section{Method}

Our sample comprises the National Health Council's (NHC) 105 member organizations. ${ }^{1}$ The NHC is a patient advocacy organization whose mission is "...to provide a united voice for the millions of people living with chronic diseases and disabilities and their family caregivers.” Its aim is to bring “... together diverse stakeholders within the health community to work for health care that meets the personal needs and goals of people with chronic diseases and disabilities” (NHC, 2015, para. 2).

Data from each organization's Twitter account were gathered for an eight-month period from January 1 through August 31, 2014. Computer code written in Python programming language (available upon request) was written to access the account-level details and the individual tweets sent by each of the NHC member organizations. These tweets were likely written and shared by NHC members for the purposes of advocating for their causes, publicizing their organizations, and interacting with their followers. These publicly available tweets provided researchers an unobtrusive way to investigate hashtag strategy and usage by NHC member organizations even though they were unaware of the research. Given recent attention concerning the ethical use of social media updates, especially journalists quoting updates in news stories, the researchers turned to the Association of Internet Research's report on ethical decision-making and internet research (Markham \& Buchanan, 2012) to ensure that the research design did not violate ethical principles. Given that no individuals are quoted in the current study and that the research focused on reporting trends, it was deemed that the research met the Association of Internet Research's criteria for ethically sound studies.

Once the tweets were downloaded, the study employed a two-stage, mixed-methods approach combining quantitative and qualitative content analyses. The first stage involved an inductive analysis of the hashtags used in each tweet to identify communication strategies unique to the social media innovation. Two researchers reviewed the data to create initial categories for the types of hashtags used by NHC organization members in their tweets. Then, they worked to reduce the amount of overlap among the categories by providing clear operational definitions of the different categories that created the final typology presented in Table 1 . Complementing this analysis was a series of quantitative content analyses used to identify the most popular hashtags and the general frequency of hashtag use. This mixed-method approach is in line with methodological literature, which sees content analysis (Krippendorf, 2004) as more appropriate for positivistic evaluations of frequency distributions and qualitative inductive analyses (Strauss \& Corbin, 1998) as more appropriate for grounded theory building.

In the second stage of the analysis, a series of regressions was used to determine the relationship between hashtag utilization and the effectiveness of organizational messaging, as reflected in the number of retweets each message receives. Collectively, these two sets of analyses allowed us to identify the types of hashtags organizations were using, how they

\footnotetext{
${ }^{1}$ Full list available at www.nationalhealthcouncil.org/pages/member-roster.php
} 
were using them, and the relative effectiveness of the hashtag communication strategies we identified.

\section{Results}

\section{Summary of NHC Organizations' Twitter Usage}

Of the 105 organizations, two did not have a Twitter account. Four others with Twitter accounts did not send a tweet during 2014. The remaining 99 organizations sent a total of 75,934 tweets from January 1 through August 31, 2014. Two of the most important measures of public engagement on social media accounts are the number of followers an organization attracts and the number of times an organizations' messages are shared, or reposted, by other users (Saxton \& Waters, 2014). The number of followers, to start, is an indication of the size of the audience the organization is attracting on social media, for followers reflect users who have made the conscious decision to connect with the organization and see its messages. Message sharing, in turn, occurs when a user finds an organization's message valuable in some way and then chooses to forward the message to the user's own followers. On Twitter, this act of sharing is called retweeting, and is a critical means of ensuring the dissemination of an organization's messages and reaching a bigger and more diverse audience (Saxton \& Waters, 2014). The average organization in our sample received 6,432 retweets during the 8-month period $(\mathrm{SD}=14,934)$; this ranged from a minimum of 1 retweet to a maximum of 87,382. The average organization had $25,040$ followers ( $S D=85,892)$ and followed 5,763 other Twitter users (SD=30,105). There was a wide range on these two variables: from 91 to 684,086 followers and from 4 to 233,212 users followed. The organizations sent on average 767 tweets ( $S D=768.5$ ) over the 8-month period (or 3.2 per day), with one organization sending as few as 2 and one as many as 3,087 (12.7 per day).

\section{Organizations’ Use of Hashtags}

Hashtag use was prevalent. The 75,934 tweets collectively contained 9,934 unique hashtags. The mean number of times hashtags were used was $853(\mathrm{SD}=969)$ and ranged from 0 to 4,720. The number of unique hashtags employed was fewer: an average organization employed 202 unique hashtags $(S D=189.8)$ in their tweets over the eightmonth period, with a range from 0 to 770 unique hashtags.

Figure 1 shows a hashtag cloud based on all the hashtags. The larger the hashtag, the more frequently it appeared in the organizations' tweets. A visual inspection shows heavy prevalence of hashtags denoting medical conditions (e.g., \#diabetes), health goals (e.g., \#endALZ), policy advocacy (e.g., \#passtheableact) and health-related events (e.g., \#icebucketchallenge) and conferences (e.g., \#asco14).

To delve into the most frequently used hashtags further, Figure 2 shows the number of times the top 25 most popular hashtags were used. The most popular hashtag, \#endALZ, was used 1,459 times by the 99 organizations over the eight-month study period. The $25^{\text {th }}$ most-popular hashtag, \#ACA, was used 402 times. 


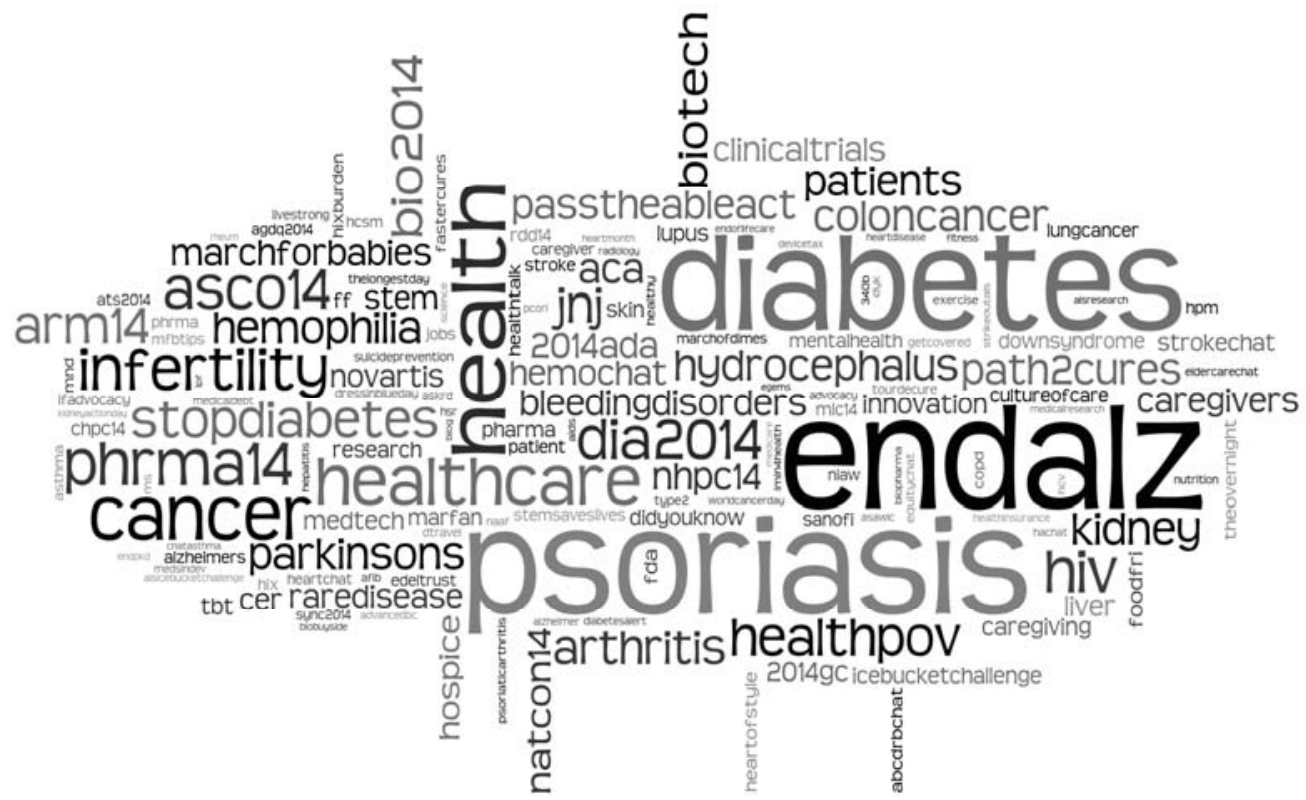

Figure 1. Hashtag cloud based on frequency of hashtags in 75,934 tweets, $1 / 1 / 14-8 / 31 / 14$

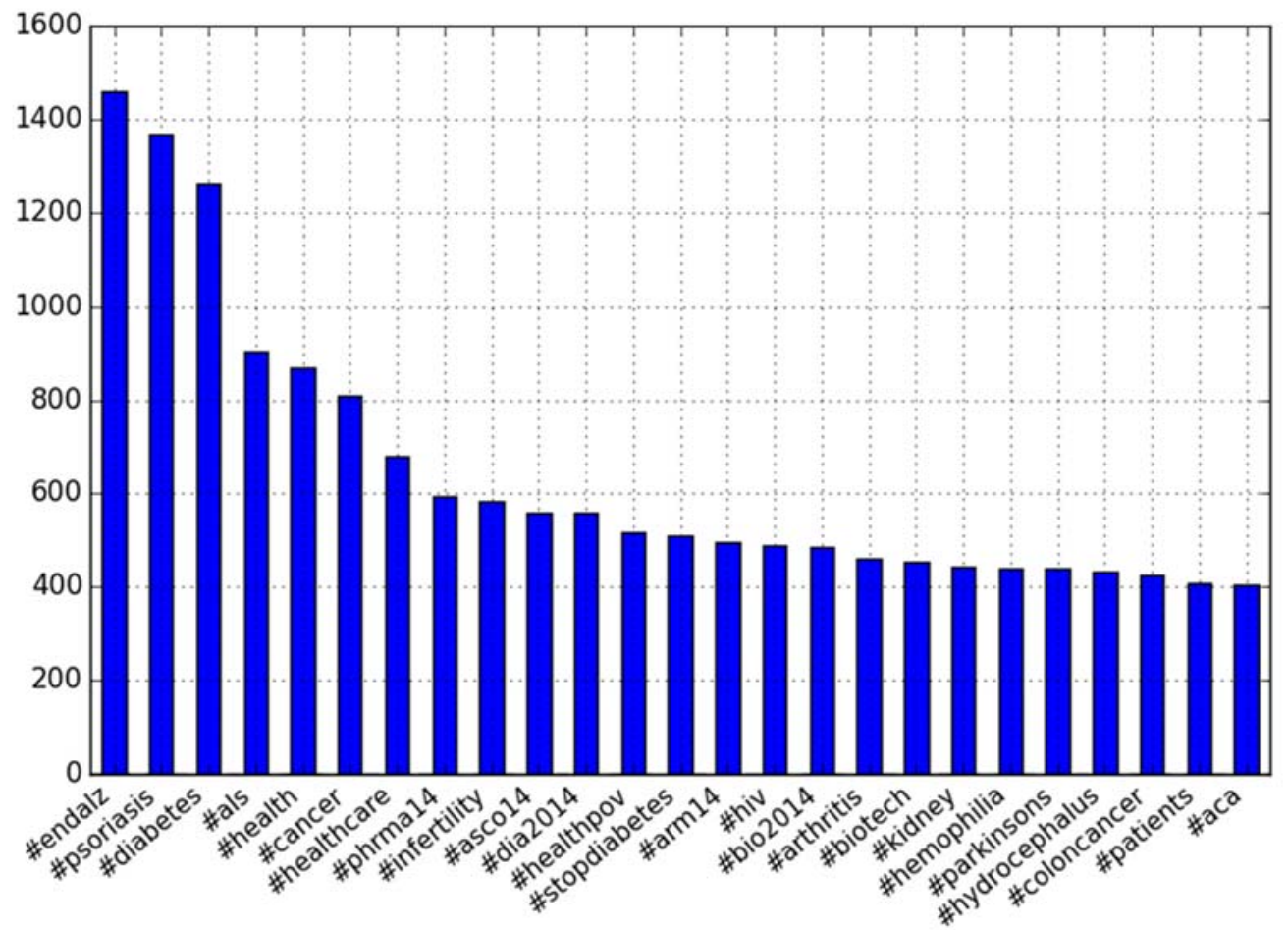

Figure 2. Frequency of use of top 25 hashtags in 75,934 tweets, 1/1/14 -8/31/14 
Figure 2 only shows the most frequently used hashtags. Not shown is that a full 5,595 of the 9,934 hashtags (56.3\%) are used only once and a further 1,250 hashtags (12.6\%) are used only twice. With another 632 being used only 3 times (6.4\%), a full $75.3 \%$ of all hashtags are only employed 1 to 3 times. Thus, there is not a normal distribution or bell curve to the frequency with which the various hashtags are employed. Instead, a few hashtags receive extremely heavy usage while the great majority of them are sparsely used.

\section{Classifying Hashtags}

To understand the types of hashtags advocacy organizations are using, the study took an inductive approach to see what categories of hashtags might help patient advocacy organizations deliver more effective messages to their target audiences. To develop the coding scheme, a random sample of 1,000 of the 75,934 tweets was analyzed. Of these tweets, 226 were retweeted messages, or messages sent by other organizations that the organizations in our sample decided to re-post. Given that the intentionality of hashtag use in such retweeted messages was less clear, the researchers decided to concentrate hand coding efforts on the 774 original tweets out of the random sample of 1,000 (83 of the 99 organizations are represented in this sample of 774 tweets). Of these 774 tweets, 264 did not contain a hashtag, while 510 contained one or more hashtags. The hashtags in these 510 tweets were hand coded individually.

Based on the inductive coding of data, the 8-category coding scheme for hashtags presented in Table 1 was developed. The table also shows how frequently each hashtag type occurred within this random sample of tweets. The most prevalent category is termed Public Education hashtags, which includes three types (medical condition, knowledge base, and policy) and account for half of the hashtags (50.4\%). The second type of hashtag is the Event hashtag (19.3\%), which often reflects fundraising and awareness-raising events. The third type of hashtag (3.2\%) is the Call-to-Action hashtag. These hashtags can be used to mobilize audiences for collective action, whether to engage in direct online or offline action or simply to assist in further disseminating its public education messages.

Tags that reflect the organization's Values and Goals (9.0\% of hashtags) are a fourth category of hashtags. Values and Goals hashtags help the organization differentiate itself from others in a way that helps serve to strengthen the organization's brand. They are related to the fifth category of hashtags, called Branding. Branding hashtags (7.2\%) employ some variant of the organization's name, its programs, or slogans unique to the organization.

Dialogic hashtags (5.0\%) serve to foster dialogue with audience members. The majority of these hashtags are chat-focused hashtags that serve as the focus for regularly scheduled chats with constituents. Others either target audience members or ask questions to produce responses. What binds these dialogic hashtags is the relationship-building role they serve (Bortree \& Seltzer, 2009; Lovejoy \& Saxton, 2012). The emphasis is not specifically on informing or mobilizing the audience but rather on building a community of like-minded constituents that can then potentially be relied on in the future to help the organization meet its advocacy mission. 
The final two types of hashtags are more descriptive. First, Time and Place hashtags (3.3\%) serve to denote a time or place important to the tweet and organization. Second, Business hashtags (2.2\%) are those related to business issues, specific sectors of the economy, or particular stocks. Hashtags that were unrelated to any of these categories and deemed off-topic to the organizations were classified as miscellaneous; however, this category only contained two hashtags.

\begin{tabular}{|c|c|c|c|}
\hline Hashtag category w/ definition & Examples & Freq & $\%$ \\
\hline \multicolumn{2}{|c|}{ 1. KNOWLEDGE \& PUBLIC EDUCATION } & 413 & $50.5 \%$ \\
\hline $\begin{array}{l}\text { Medical condition-hashtag denoting } \\
\text { disease or medical condition }\end{array}$ & \#diabetes, \#Hemophilia, \#psoriasis & $(153)$ & $(18.7 \%)$ \\
\hline $\begin{array}{l}\text { Knowledge base-health-related } \\
\text { research, knowledge, education }\end{array}$ & $\begin{array}{l}\text { \#hearthealthy, \#AsthmaAwareness, } \\
\text { \#ALSresearch }\end{array}$ & $(231)$ & $(28.2 \%)$ \\
\hline $\begin{array}{l}\text { Policy-health-related public policy, } \\
\text { public policy issues }\end{array}$ & $\begin{array}{l}\text { \#SunshineAct, \#DeviceTax, } \\
\text { \#HCCosts }\end{array}$ & (29) & $(3.5 \%)$ \\
\hline $\begin{array}{l}\text { 2. EVENTS-health-related event, } \\
\text { conference, holiday }\end{array}$ & $\begin{array}{l}\text { \#WorldCancerDay, } \\
\text { \#WalktoCureArthritis, } \\
\text { \#ALSIceBucketChallenge }\end{array}$ & 158 & $19.3 \%$ \\
\hline $\begin{array}{l}\text { 3. VALUES AND GOALS- } \\
\text { organizational values or goals. Useful } \\
\text { for reinforcing the organization's core } \\
\text { values and ultimate strategic goals. }\end{array}$ & $\begin{array}{l}\text { \#StopDiabetes, \#PatientAccess, } \\
\text { \#coloncanceradvocate }\end{array}$ & 74 & $9.0 \%$ \\
\hline $\begin{array}{l}\text { 4. BRANDING-organization-specific } \\
\text { hashtags, unique organization } \\
\text { identifiers, hashtags noting one of the } \\
\text { organization's program names }\end{array}$ & $\begin{array}{l}\text { \#ShowUpDifferently, } \\
\text { \#MerckOncology, \#UHFscholars }\end{array}$ & 59 & $7.2 \%$ \\
\hline $\begin{array}{l}\text { 5. DIALOGIG-“chat” and dialogue } \\
\text { hashtags }\end{array}$ & $\begin{array}{l}\text { \#HeartChat, \#HemoChat, } \\
\text { \#DidYouKnow? }\end{array}$ & 41 & $5.0 \%$ \\
\hline $\begin{array}{l}\text { 6. TIME AND PLACE-any time or } \\
\text { location hashtag }\end{array}$ & \#PuertoRico, \#Summer, \#Capitol & 27 & $3.3 \%$ \\
\hline $\begin{array}{l}\text { 7. CALL-TO-ACTION-hashtags } \\
\text { asking audience to do something }\end{array}$ & $\begin{array}{l}\text { \#ShareForAwareness, } \\
\text { \#HugDontJudge, \#Raise100K }\end{array}$ & 26 & $3.2 \%$ \\
\hline \multirow{2}{*}{$\begin{array}{l}\text { 8. BUSINESS-related to business } \\
\text { issues, stocks, companies, etc. } \\
\text { Captures a wide range of non-health, } \\
\text { non-advocacy-related hashtags, used } \\
\text { in the sample }\end{array}$} & \#Biotech, \#GM, \#Stocks & 18 & $2.2 \%$ \\
\hline & Total & 818 & \\
\hline
\end{tabular}

Note: Frequencies are the number of times each hashtag type was used in the 510 of 1,000 randomly selected tweets that were original (i.e., were not themselves retweets, $n=774$ ) and contained a hashtag $(\mathrm{n}=510)$. A total of 818 hashtags were included in these 510 tweets; percentages indicate proportions relative to these 818 hashtags. Not shown is a miscellaneous category in which 2 hashtags (\#FREE, \#adoption) were placed. 


\section{Comparing Hashtag Use Across Organizations}

The NHC organizes its members into five categories: Patient Advocacy Organizations $(n=46)$, Nonprofit Organizations with Health Interests $(n=9)$, Professional and Membership Associations $(n=24)$, Business and Industry $(n=23)$, and Associate Members $(n=2)$. From a representational standpoint, the first two are heavily invested in patient advocacy, the middle category represents professional interests, while the final two for-profit categories focus more on representing business interests. For analysis purposes we considered three types of organizations: 1) patient advocacy nonprofits, 2) professional interest organizations, and 3) business interest organizations.

The Venn diagram in Figure 3 shows the intersection of the 9,934 hashtags used across the three organization types. For instance, the patient advocacy organizations used 4,756 hashtags that were never employed by any business interest or professional interest organization over the 8-month period, 351 hashtags that were used by professional interest but not business interest organizations, and 462 hashtags that were used by business interest but not professional interest organizations. There were 386 hashtags that were crosssectoral, that is, not limited to use by just one sector or category of organization. In the multiple regressions, this idea resurfaces during examinations of the effectiveness of hashtags.

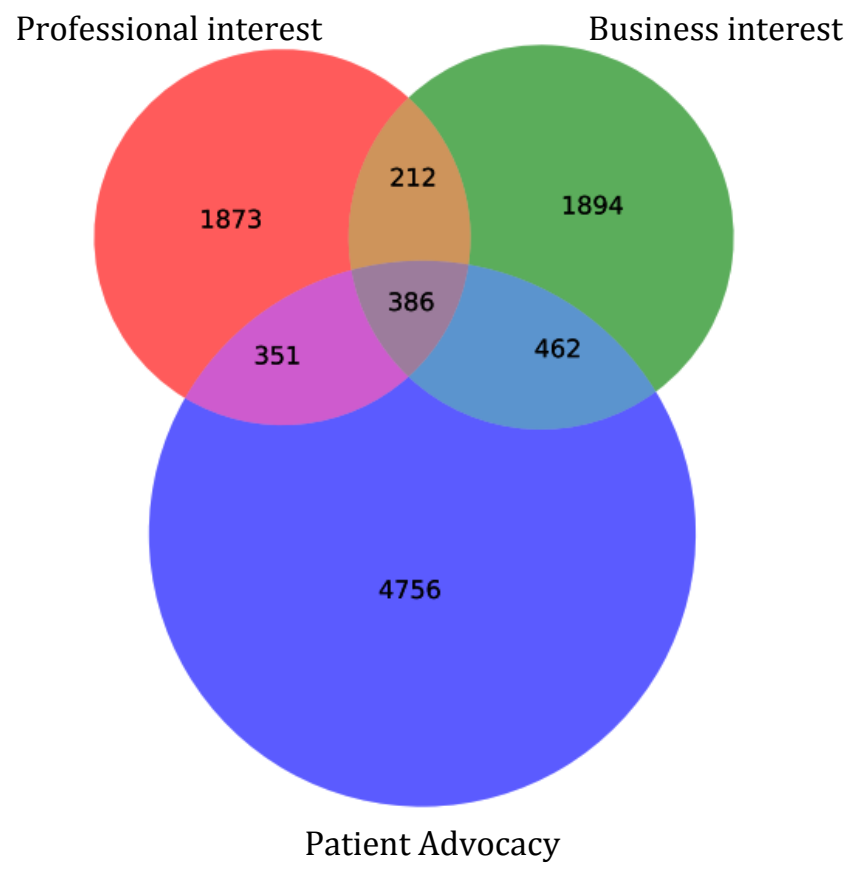

Figure 3. Number of hashtags used in common across the 3 main organization types 


\section{Relationship Between Hashtag Use and Message Effectiveness}

A series of regressions are used to examine the relationship between the organizations' use of hashtags and the effectiveness of the organizations' messages. Specifically, the analyses examine whether the use of hashtags leads to greater advocacy message effectiveness and which types of hashtags are most effective.

Dependent Variable. Our dependent variable for the regressions is audience engagement with organizations' messages as measured by the number of retweets each message receives. Table 2 contains summary statistics for the retweet count variable along with all other variables included in the regressions. There is substantial variability in the number of retweets a message receives. While the average is 3.58 retweets, the standard deviation is 11.49 and the range is from 0 to 897.

\begin{tabular}{|c|c|c|c|c|c|}
\hline & \# Obs. & Mean & SD & Min & Max \\
\hline \multicolumn{6}{|l|}{ Message Attention Measure } \\
\hline Retweet Count & 60,919 & 3.58 & 11.49 & 0 & 897 \\
\hline \multicolumn{6}{|l|}{ Hashtag Counts } \\
\hline \# Hashtags & 60,919 & 1.0911 & 1.03 & 0 & 10 \\
\hline Sector-spanning Hashtag & 60,919 & 0.24 & 0.43 & 0 & 1 \\
\hline \multicolumn{6}{|l|}{ Hashtag Type } \\
\hline Public Education & 774 & 0.35 & 0.48 & 0 & 1 \\
\hline Event & 774 & 0.20 & 0.40 & 0 & 1 \\
\hline Call-to-action & 774 & 0.03 & 0.18 & 0 & 1 \\
\hline Values and Goals & 774 & 0.09 & 0.28 & 0 & 1 \\
\hline Branding & 774 & 0.07 & 0.26 & 0 & 1 \\
\hline Chat \& Dialogue & 774 & 0.05 & 0.22 & 0 & 1 \\
\hline Time or Place & 774 & 0.03 & 0.17 & 0 & 1 \\
\hline Business & 774 & 0.02 & 0.13 & 0 & 1 \\
\hline \multicolumn{6}{|l|}{ Tweet-level Controls } \\
\hline \# URLs & 60,919 & 0.65 & 0.50 & 0 & 4 \\
\hline \# User mentions & 60,919 & 0.72 & 1.03 & 0 & 11 \\
\hline \# Characters & 60,919 & 112.92 & 28.10 & 5 & 153 \\
\hline Photo & 60,919 & 0.08 & 0.27 & 0 & 1 \\
\hline Video link & 60,919 & 0.01 & 0.08 & 0 & 1 \\
\hline \multicolumn{6}{|l|}{ Account-level controls } \\
\hline \# Followers & 60,919 & 46.33 & 117.96 & .09 & 684,09 \\
\hline \# Tweets (to 12/2013) & 60,919 & $5,084.12$ & $3,788.51$ & 12 & 14,589 \\
\hline Time on Twitter (\# days) & 60,919 & $1,838.91$ & 387.89 & 331 & 2,689 \\
\hline
\end{tabular}

Multiple Regressions. Table 3 presents results from a series of four negative binomial regressions. In each model the dependent variable is the number of retweets each tweet receives. Each model contains the same suite of account-level and tweet-level control variables shown to be significant predictors of social media message sharing (Saxton \& 
Waters, 2014). What varies in each model is the specific hashtag-related variable. In Model 1 , the key independent variable is the number of hashtags contained in each tweet while the main independent variable in Model 2 is a binary variable indicating the presence of a sector-spanning hashtag. In Model 3, the primary independent variables are a series of dummy variables representing the 8 hashtag types in Table 2. Finally, all the abovementioned independent variables are included in Model 4.

\begin{tabular}{|c|c|c|c|c|c|c|c|c|}
\hline \multirow[b]{3}{*}{$\begin{array}{l}\text { Hashtag Frequency } \\
\text { \# Hashtags }\end{array}$} & \multicolumn{2}{|c|}{$\begin{array}{c}(1) \\
\text { IV=Hashtag } \\
\underline{\text { Count }}\end{array}$} & \multicolumn{2}{|c|}{$\begin{array}{c}(2) \\
\underline{\mathrm{IV}=\text { Common }} \\
\underline{\text { Hashtag }}\end{array}$} & \multicolumn{2}{|c|}{$\begin{array}{c}(3) \\
\frac{\text { IVs=Hashtag }}{\text { Type }}\end{array}$} & \multicolumn{2}{|c|}{$\begin{array}{c}(4) \\
\text { Combined model }\end{array}$} \\
\hline & Coeff. & $\underline{\mathrm{SE}}$ & Coeff. & $\underline{\mathrm{SE}}$ & Coeff. & $\underline{\mathrm{SE}}$ & Coeff. & $\underline{\mathrm{SE}}$ \\
\hline & $0.13^{* *}$ & $(0.01)$ & & & & & -0.17 & $(0.11)$ \\
\hline $\begin{array}{l}\text { Cross-Sector Hashtag } \\
\text { Common Hashtag }\end{array}$ & & & $0.14^{* *}$ & $(0.02)$ & & & $0.30^{*}$ & $(0.15)$ \\
\hline $\begin{array}{l}\text { Hashtag Type } \\
\text { Public Education } \\
\text { Values and Goals } \\
\text { Branding } \\
\text { Time or Place } \\
\text { Call to Action } \\
\text { Chat } \\
\text { Event }\end{array}$ & & & & & $\begin{array}{l}0.57^{* *} \\
0.46^{*} \\
0.37 \\
-0.41 \\
0.51 \\
0.35 \\
-0.17\end{array}$ & $\begin{array}{l}(0.12) \\
(0.20) \\
(0.23) \\
(0.34) \\
(0.33) \\
(0.25) \\
(0.15)\end{array}$ & $\begin{array}{l}0.71^{* *} \\
0.52^{*} \\
0.57^{*} \\
-0.17 \\
0.70^{*} \\
0.48^{+} \\
-0.01\end{array}$ & $\begin{array}{l}(0.21) \\
(0.23) \\
(0.25) \\
(0.36) \\
(0.34) \\
(0.28) \\
(0.19)\end{array}$ \\
\hline $\begin{array}{l}\text { Tweet controls } \\
\text { \# URLs } \\
\text { \# User mentions } \\
\text { \# Characters } \\
\text { Photo } \\
\text { Video link }\end{array}$ & $\begin{array}{l}0.21^{* *} \\
-0.30^{* *} \\
0.01^{* *} \\
1.11^{* *} \\
0.72^{* *}\end{array}$ & $\begin{array}{l}(0.01) \\
(0.01) \\
(0.00) \\
(0.02) \\
(0.08)\end{array}$ & $\begin{array}{l}0.17^{* *} \\
-0.31^{* *} \\
0.01^{* *} \\
1.11^{* *} \\
0.74^{* *}\end{array}$ & $\begin{array}{l}(0.01) \\
(0.01) \\
(0.00) \\
(0.02) \\
(0.08)\end{array}$ & $\begin{array}{c}-0.03 \\
-0.38^{* *} \\
0.01^{* *} \\
1.29^{* *} \\
-20.99\end{array}$ & $\begin{array}{c}(0.14) \\
(0.07) \\
(0.00) \\
(0.22) \\
(19830.9)\end{array}$ & $\begin{array}{c}-0.08 \\
-0.41^{* *} \\
0.01^{* *} \\
1.27^{* *} \\
-18.91\end{array}$ & $\begin{array}{c}(0.14) \\
(0.07) \\
(0.00) \\
(0.22) \\
(7067.4)\end{array}$ \\
\hline $\begin{array}{l}\text { Account controls } \\
\text { \# Followers }(1,000 \mathrm{~s}) \\
\text { \# Tweets } \\
\text { Time on Twitter }\end{array}$ & $\begin{array}{l}0.004^{* *} \\
0.0001^{* *} \\
0.0003^{* *}\end{array}$ & $\begin{array}{l}(0.0001) \\
(0.0001) \\
(0.0001)\end{array}$ & $\begin{array}{l}0.003^{* *} \\
0.0001^{* *} \\
0.0003^{* *}\end{array}$ & $\begin{array}{l}(0.0001) \\
(0.0001) \\
(0.0001)\end{array}$ & $\begin{array}{l}0.003^{* *} \\
0.0001^{* *} \\
0.0005^{* *}\end{array}$ & $\begin{array}{l}(0.0005) \\
(0.0001) \\
(0.0001)\end{array}$ & $\begin{array}{l}0.003^{* *} \\
0.0001^{* *} \\
0.0005^{* *}\end{array}$ & $\begin{array}{l}(0.0005) \\
(0.0001) \\
(0.0001)\end{array}$ \\
\hline Constant & $-1.59^{* *}$ & $(0.05)$ & $-1.57^{* *}$ & $(0.05)$ & $-1.60^{* *}$ & $(0.38)$ & $-1.49^{* *}$ & $(0.38)$ \\
\hline $\begin{array}{l}N \\
\text { Pseudo } R^{2} \\
\text { Log likelihood } \\
\text { Model Sig. }\left(\chi^{2}\right)\end{array}$ & $\begin{array}{r}60 \\
0 \\
-125 \\
1531\end{array}$ & $\begin{array}{l}919 \\
22 \\
02.09 \\
5.55^{* *}\end{array}$ & $\begin{array}{r}60 \\
0 \\
-125 \\
1504\end{array}$ & $\begin{array}{l}919 \\
22 \\
37.93 \\
3.87^{* *}\end{array}$ & & $\begin{array}{l}74 \\
.26 \\
09.51 \\
1.54^{* *}\end{array}$ & $\begin{array}{r}7 \\
0 \\
-160 \\
241\end{array}$ & $\begin{array}{l}74 \\
27 \\
6.11 \\
33^{* *}\end{array}$ \\
\hline $\begin{array}{l}{ }^{+} p<0.10,{ }^{*} p<0.05,{ }^{* *} \\
\text { Business. }\end{array}$ & 0.01 & ard el & in paren & . & (h) & chts & ory & del $3 \mathrm{i}$ \\
\hline
\end{tabular}


The results are highly robust to these alternative specifications. In the first two models, conducted on the entire database of 60,919 original tweets $(15,015$ of the 74,934 tweets were retweeted/non-original messages and were thus excluded from these analyses), the coefficient on the hashtag variable is significant. In both models-controlling for the number of followers, time on Twitter, and the cumulative number of retweets sent, along with the length of the tweet and whether the tweet contains a photo, video, URL, or user mention-the hashtag measure is associated with significantly more retweets than when a hashtag is absent. In particular, again controlling for the account-level and tweet-level measures just listed, a message is likely to receive significantly more retweets the more hashtags are included (Model 1) and if the tweet contains a cross-sectoral hashtag (Model 2).

Models 3 and 4, in turn, are conducted on the random sample of 774 hand-coded tweets. In both models the omitted category is Business hashtags. ${ }^{2}$ Thus, this is the baseline category against which the other hashtag dummy variables are compared. In Model 3, the coefficients on two hashtag category variables are significant: Public Education and Values and Goals. In Model 4, the coefficients on the "sector-spanning" variable and four hashtag category variables are significant: Public Education, Values and Goals, Branding, and Call-to-Action. This means that tweets with a sector-spanning hashtag are significantly more likely to be retweeted by the organization's constituents and that tweets with a public education hashtag, a hashtag related to organizations' values or goals, a branding hashtag, or a call-to-action hashtag are significantly more likely to be retweeted by the organization's constituents when compared to tweets with a business-related hashtag.

The results for control variables are consistent across the four models. In all models retweets are associated with tweets that do not contain user mentions, are longer, contain photos, and which are sent by organizations with more followers, have been on Twitter longer, and have sent more tweets. In two of the four models, the inclusion of hyperlinks and video links is also positively associated with retweeting behavior.

\section{Discussion}

This study examined hashtag use by the 105 members of the National Health Council, a national US-based patient/health advocacy coalition. The study makes several significant contributions to the current literature. First, it improves scholars' understanding of the use of hashtags in social media advocacy by presenting an inductive coding scheme of the types of hashtags employed. Of the eight categories of hashtags, public education hashtags are far more frequently used than any other. Such hashtags focus on educating the public, a key, long-term advocacy tactic and one for which social media is particularly well suited (Guo \& Saxton, 2014). However, some of the less-frequently-used hashtag types deserve special attention, as they suggest interesting potential for the organization. Values and

\footnotetext{
2 In a regression equation with a series of dummy (binary) variables it is typically necessary to omit one of the dummy variables. That variable serves as the baseline against which the regression coefficients for the other dummy variables may be compared.
} 
Branding hashtags, for example, help the organization differentiate itself from others in a way that helps to strengthen understanding of the organization.

Second, this study compares the different ways organizations can use hashtags to enhance the effectiveness of social media advocacy as measured by the number of retweets each message receives. Three distinctive strategies of using hashtags were identified. The first strategy is simply to play the numbers game; that is, to increase the number of hashtags in a single tweet to boost the number of retweets. The second, and arguably more sophisticated strategy, is to find common ground with partners across sectors. This common-ground strategy focuses on identifying and including sector-spanning hashtags in a tweet. A third strategy refers to the selective use of certain types of hashtags. For example, the organization might choose to include particular types of hashtags (e.g., call-to-action hashtags) believed to be more noticed by followers.

In the regression analyses, the effectiveness of these three strategies was tested and had significant and positive effects on the dependent variable (number of retweets received) when tested separately, offering evidence that each of the hashtag strategies helps to increase the level of audience engagement. When tested together, the significance of the hashtag count variable disappears; however, the sector-spanning variable and several hashtag type variables (i.e., public education, values and goals, branding, call-to-action, and chat and dialogue) were significant. This finding suggests that, among the three strategies, it is not the number of hashtags but rather the type of hashtags used that really matters.

Given that the type of hashtags is critical to social media success, it may be helpful to conclude the current study with a brief review of suggested best practices for using hashtags to advance organizational and advocacy messaging. First, it is necessary to use hashtags that are likely to advance the organization's cause. Although an organization can use generic hashtags, such as \#cancer, organizational messaging becomes more memorable and serves for better brand recognition when a hashtag is more specific, such as \#FindaCure or \#CancerSucks (Ma, Sun, \& Cong, 2013). When creating hashtags, organizations should ensure that they are not using a hashtag that has been trademarked or used before. Reviewing hashtag directories like www.Twubs.com can help organizations avoid using hashtags that are already in use by other campaigns. Additionally, potential hashtags should be reviewed internally by an organization's communications team and leadership, but they should also be tested with a few close outsiders (e.g., volunteers, key donors) to make sure that any potential social media mishap is averted.

Once an organization selects its hashtag, the next challenge is to grow a community around that hashtag. While regular usage of the hashtag may help increase the public's association of the hashtag with a specific organization, it is more important to have active social media consumers also using the hashtag in positive messaging surrounding the cause and organization (Kywe, Hoang, Lim, \& Zhu, 2012). Organizations should consider how they can use hashtags to get individuals involved with an advocacy effort by creating a personal user experience-not simply focusing on the organization. For example, the Red Cross could have simply used the hashtag \#npm14 to promote its campaign for "National Preparedness Month” in September, 2014. However, \#npm14 became a widely successful 
hashtag because users were encouraged to share how they were preparing for natural disasters.

Finally, regardless of what hashtag strategy an organization chooses, it is necessary to monitor how the hashtag is used by the public. Continued evaluation of the hashtag's usage is important for multiple reasons. First, it can be used to help determine what message points are reverberating among targeted audiences. These messages then can be used in other advocacy efforts to reiterate key messages to prompt further interactivity and engagement for the issue. On the other hand, if a hashtag has not been successful in generating interest in the organization, cause, or campaign, it can be retired and replaced by one that may generate that interest (Kwye et al., 2012). Second, it is helpful to see how the hashtag is being used by others so that campaigns can be cancelled if a hashtag has been used in a mocking manner. For example, in promoting nutrition in schools across the nation, first lady Michelle Obama spoke about the importance of healthy lunches and mentioned that students could share their \#healthylunch using that hashtag; however, the hashtag usage was quickly overrun with pictures of questionable school lunches and accompanied by a sarcastic \#ThanksMichelleObama hashtag. Monitoring may not be able to end mocking and scorn on social media, but it can empower the organization to address points of concern that are expressed by social media users.

Finally, the monitoring should be carried out across the social web. Even though this study focuses on Twitter hashtags, the hashtag has become commonplace across most social media platforms. An organization's campaign that started on Twitter may very well find its way to Instagram, Pinterest, YouTube, and Facebook. An organization that wants to become active in advocacy efforts must remember that social media platforms are interconnected, thus hashtag usage must be reviewed on all potential platforms to avoid potential communication blunders.

This study also has implications for social work practice. For organizations that aspire to excel in their advocacy work on social media, tweets will get retweeted and noticed if they use sector-spanning hashtags. Likewise, hashtags that educate the public, communicate core organizational values and goals, and engage the audience into action or dialogue are more likely to be shared with others. This study is a first step to fully understanding the strategic use of hashtags in social media advocacy. Future research should test the classification scheme in other domains as well as interview social media advocates and marketers to determine whether the classification scheme aligns with their motivations for using hashtags.

\section{References}

Anstadt, S. P., Burnette, A., \& Bradley, S. (2011). Towards a research agenda for social work practice in virtual worlds. Advances in Social Work, 12(2), 289-300.

Bortree, D. S., \& Seltzer, T. (2009). Dialogic strategies and outcomes: An analysis of environmental advocacy groups’ Facebook profiles. Public Relations Review, 35(3), 317-319. doi: 10.1016/j.pubrev.2009.05.002 
Bruns, A., \& Burgess, J. E. (2011, August). The use of Twitter hashtags in the formation of ad hoc publics. Paper presented at the 6th European Consortium for Political Research General Conference, University of Iceland, Reykjavik.

Edwards, H. R., \& Hoefer, R. (2010). Are social work advocacy groups using Web 2.0 effectively? Journal of Policy Practice, 9(3-4), 220-239.

Goldkind, L. (2014). E-advocacy in human services: The impact of organizational conditions and characteristics on electronic advocacy activities among nonprofits. Journal of Policy Practice, 13(4), 300-315.

Goldkind, L., \& McNutt, J. G. (2014). Social media and social change: Nonprofits and using social media strategies to meet advocacy goals. In A.-M. José Antonio \& L.-C. Ana María (Eds.), ICT management in non-profit organizations (pp. 56-72). Hershey, PA, USA: IGI Global.

Guo, C., \& Saxton, G. D. (2010). Voice-in, voice-out: Constituent participation and nonprofit advocacy. Nonprofit Policy Forum, 1(1), Article 5. Retrieved from http://www.bepress.com/npf/vol1/iss1/5

Guo, C., \& Saxton, G. D. (2014). Tweeting social change: How social media are changing nonprofit advocacy. Nonprofit and Voluntary Sector Quarterly, 43(1), 5779. doi: 10.1177/0899764012471585

Hick, S., \& McNutt, J. G. (2002). Advocacy, activism, and the Internet: Community organization and social policy. Chicago: Lyceum.

Kirkpatrick, M. (2011). The first hashtag ever tweeted on Twitter: They sure have come a long way. Retrieved February 4, 2011, from ReadWriteWeb.com website http://bit.ly/1BnGNwV

Krippendorff, K. (2004). Content analysis: An introduction to its methodology. London: Sage Publications, Inc.

Kywe, S. M., Hoang, T.-A., Lim, E.-P., \& Zhu, F. (2012). On recommending hashtags in Twitter networks. Social Informatics, 7710, 337-350.

Lovejoy, K., \& Saxton, G. D. (2012). Information, community, and action: How nonprofit organizations use social media. Journal of Computer-Mediated Communication, 17(3), 337-353.

Ma, Z., Sun, A., \& Cong, G. (2013). On predicting the popularity of newly emerging hashtags in Twitter. Journal of the American Society for Information Science and Technology, 64(7), 1399-1410.

Markham, A., \& Buchanan, E. (2012). Ethical decision-making and Internet research. Retrieved February 19, 2015, from http://aoir.org/reports/ethics2.pdf

McNutt, J. G. (2008). Advocacy organizations and the organizational digital divide. Currents: New Scholarship in the Human Services, 7(2), 1-13. 
Mosley, J. (2013). Recognizing new opportunities: Reconceptualizing policy advocacy in everyday organizational practice. Social Work, 58(3), 231-239.

National Health Council. (2015). About the National Health Council. Retrieved from http://www.nationalhealthcouncil.org/about-nhc

Obar, J. A., Zube, P., \& Lampe, C. (2012). Advocacy 2.0: An analysis of how advocacy groups in the United States perceive and use social media as tools for facilitating civic engagement and collective action. Journal of Information Policy, 2, 1-25.

Perron, B. E., Taylor, H. O., Glass, J. E., \& Margerum-Leys, J. (2010). Information and communication technologies in social work. Advances in Social Work, 11(2), 67-81.

Queiro-Tajalli, I., Campbell, C., \& McNutt, J. (2003). International social and economic justice and on-line advocacy. International Social Work, 46(2), 149-161.

Saxton, G. D., \& Waters, R. D. (2014). What do stakeholders like on Facebook? Examining public reactions to nonprofit organizations' informational, promotional, and community-building messages. Journal of Public Relations Research, 26(3), 280-299. doi: 10.1080/1062726x.2014.908721

Strauss, A., \& Corbin, J. (1998). Basics of qualitative research (2 ed.). Thousands Oaks, CA: Sage.

Waters, R. D., \& Jamal, J. Y. (2011). Tweet, tweet, tweet: A content analysis of nonprofit organizations’ Twitter updates. Public Relations Review, 37(3), 321-324. doi: 10.1016/j.pubrev.2011.03.002

\section{Author note}

Correspondence concerning this article should be addressed to Gregory D. Saxton, Department of Communication, University at Buffalo, SUNY, 331 Baldy Hall, Buffalo, New York 14260-1020. Tel: (716) 645-1161. Email: gdsaxton@buffalo.edu 